\title{
Effects of fungal-assisted algal harvesting through biopellet formation on pesticides in water
}

\author{
Malin Hultberg - Hristina Bodin
}

Received: 12 October 2017 / Accepted: 29 August 2018/Published online: 1 September 2018

(C) The Author(s) 2018

\begin{abstract}
Recent research has demonstrated the potential of using filamentous fungi to form pellets with microalgae (biopellets), in order to facilitate harvesting of microalgae from water following algaebased treatment of wastewater. In parallel, there is a need to develop techniques for removing organic pollutants such as pesticides and pharmaceuticals from wastewater. In experiments using the microalga Chlorella vulgaris, the filamentous fungus Aspergillus niger and biopellets composed of these microorganisms, this study investigated whether fungal-assisted algal harvesting can also remove pesticides from contaminated water. A mixture of 38 pesticides was tested and the concentrations of 17 of these were found to be reduced significantly in the biopellet treatment, compared with the control. After harvesting, the concentration of total pesticides in the algal treatment did not differ significantly from that in the control.
\end{abstract}

Electronic supplementary material The online version of this article (https://doi.org/10.1007/s10532-018-9852-y) contains supplementary material, which is available to authorized users.

M. Hultberg $(\bowtie)$

Department of Biosystems and Technology, Swedish University of Agricultural Sciences, P.O. Box 103, 23053 Alnarp, Sweden

e-mail: Malin.Hultberg@slu.se

H. Bodin

Division of Natural Sciences, Kristianstad University, Kristianstad, Sweden
However, in the fungal treatment and biopellet treatment, the concentration was significantly lower $(59.6 \pm 2.0 \mu \mathrm{g} / \mathrm{L}$ and $56.1 \pm 2.8 \mu \mathrm{g} / \mathrm{L}$, respectively $)$ than in the control $(66.6 \pm 1.0 \mu \mathrm{g} / \mathrm{L})$. Thus fungalassisted algal harvesting through biopellet formation can also provide scope for removing organic pollutants from wastewater, with removal mainly being performed by the fungus.

Keywords Aspergillus niger - Bioremediation · Chlorella vulgaris · Emerging pollutants · Water quality

\section{Introduction}

The world's population is increasing rapidly and waste streams such as municipal wastewater are being produced in ever increasing quantities. This has generated interest in developing sustainable technologies with low energy demand for municipal wastewater treatment that allow recirculation of resources, such as nutrients needed for crop production. One possibility is algae-based technologies such as highrate algal ponds, which are well-known for removal of inorganic nutrients from wastewater (Oswald 1988; Shilton et al. 2012). Another positive aspect of using microalgae for wastewater treatment is that the biomass obtained after treatment can be an economic 
benefit if used within the emerging biofuel sector (Gentili 2014).

A current bottleneck in using microalgae for treatment of wastewater is the harvesting step, which requires methods such as filtration, chemical flocculation and centrifugation. These harvesting methods may account for as much as $20-30 \%$ of the total algal biomass production costs and are also very energydemanding (Uduman et al. 2010). Recent research has indicated the potential for using filamentous fungi to form pellets with microalgae (biopellets) in order to advance the sustainability and economic feasibility of producing and harvesting microalgal biomass in wastewater (Zhang and $\mathrm{Hu}$ 2012; Bhattacharya et al. 2017).

In parallel, studies over the past decade have shown that conventional wastewater treatment processes only partly remove organic pollutants such as pesticides and pharmaceuticals (Jones et al. 2005; Hollender et al. 2009; Pereira et al. 2015). These substances are now frequently detected in aquatic ecosystems (Loos et al. 2009; Masiá et al. 2013), and in groundwater and drinking water (Loos et al. 2010a). Thus, there is also a need to develop methods for removing organic pollutants from water, especially methods with high efficiency when treating dilute effluents. European Union Directive 2013/39/EU set by the European Commission (EC 2013) highlights this need in order to combat priority compounds, which include several pesticides. Methods such as ozonation and active carbon filtration have been demonstrated to be efficient in removing organic pollutants (Hollender et al. 2009). In some situations, wastewater treatment techniques based on biological processes could also be a low-cost alternative.

One sustainable and low-cost method for treatment of water contaminated with organic pollutants, such as pesticides, is through use of naturally occurring microorganisms. Reductions in organic pollutant concentrations in water can be achieved through initial and rapid biosorption onto the microorganism biomass and through biodegradation of the pollutant (Fomina and Gadd 2014). Microalgae and fungi have both been demonstrated to effectively remove pesticides from water (Cai et al. 2007; Pinto et al. 2012; Yakout 2014; Hultberg et al. 2016). For microalgae, the effect can be partly explained by a synergistic relationship between the photosynthetic microalgae and heterotrophic bacteria degrading the pollutant
(Muñoz and Guieysse 2006). For fungi, certain species are of high interest for bioremediation of media contaminated with organic pollutants due to their production of extracellular enzymes, such as laccases, capable of degrading recalcitrant xenobiotics (Viswanath et al. 2014). Removal of pesticides from water by microorganisms generally follows first-order kinetics, where the removal rate is directly correlated to the pollutant concentration (Cai et al. 2007). The pesticide levels normally found in contaminated aquatic ecosystems are low for individual substances, often at levels below $5 \mu \mathrm{g} / \mathrm{L}$ (Kreuger et al. 2010), but still well above the maximum acceptable limits stated in the EU watchlist of priority substances (EC 2015).

The use of filamentous fungi for harvesting microalgae, through formation of biopellets, is currently being intensely researched (Bhattacharya et al. 2017) and has high potential for being developed into a sustainable technology. The aim of the present study was to investigate the effect of this harvesting process on pesticide removal from contaminated water. The experiments were performed at low pesticide concentrations using a mixture of pesticides from different substance groups and the microalga Chlorella vulgaris and the filamentous fungus Aspergillus niger.

\section{Materials and methods}

\section{Microorganisms}

The microalgal species Chlorella vulgaris strain 211/11B from CCAP-SAMS (Culture Collection of Algae and Protozoa, The Scottish Association for Marine Science), Scotland, and the filamentous fungus Aspergillus niger ATCC ${ }^{\circledR} 16888^{\mathrm{TM}}$ from the American Type Culture Collection were used in the study.

The microalgal strain was cultivated in BG-11 medium (Zhang and $\mathrm{Hu}$ 2012). The algal culture was started by inoculating BG-11 medium with $10 \%$ (v/v) of a $C$. vulgaris culture taken from a 4-day-old algal culture. The culture was maintained in a greenhouse at $20{ }^{\circ} \mathrm{C}$ (photoperiod $16 \mathrm{~h}$ ) and illumination of $50 \mu \mathrm{mol} / \mathrm{m}^{2} \mathrm{~s}$ (PAR). The culture was aerated $(0.3$ vvm) to prevent the algal cells from settling. After 4 days, the number of algal cells was determined by counting in a Bürkner chamber and a stock solution containing $2.0 \times 10^{7}$ cells $/ \mathrm{mL}$ was made using BG-11 medium. 
Fungal spores were cultivated on petri plates with potato dextrose agar (PDA) at room temperature for 10 days. The spores were harvested by applying $3 \times 10 \mathrm{~mL}$ of glucose solution $(20 \mathrm{~g} / \mathrm{L})$ directly onto the PDA plates using a sterile syringe. The spore solution was filtered through a nylon filter (mesh size $100 \mu \mathrm{m}$ ). The number of fungal spores was determined by counting in a Bürkner chamber and a stock solution containing $3.9 \times 10^{5}$ fungal spores $/ \mathrm{mL}$ was prepared.

Both the algal and the fungal stock solution were kept at $4{ }^{\circ} \mathrm{C}$ in darkness until the start of the experiment on the same day. Biopellets were formed by mixing equal amounts of microalgae stock solution and fungal stock solution (Zhang and $\mathrm{Hu} 2012$ ).

\section{Selected pesticides}

A pesticide mixture (Mix M2101/1B, Analytical Reference Material, Restek, USA) was obtained from the Centre for Chemical Pesticides (CKB), Swedish University of Agricultural Sciences, Ultuna. This mixture contained one plant growth regulator (trinexapac ethyl) and the following 37 pesticides: acetamiprid, carbofuran, carfentrazone ethyl, chlorfenvinphos, cyanazine, clomazone, cloridazon, cyazofamid, cyprodinil, difenoconazole, ethofumesate, fenpropidin, fludioxonil, flurprimidol, flurtamone, flusilazole, flutriafol, fuberidazole, hexazinone, imidachloprid, mandipropamid, metalaxyl, metamitron, metazachlor, metolachlor, metrafenone, penconazole, phenmedipham, pirimicarb, propamocarb, propyzamide, protioconazole-destio, pyroxsulam, quinmerac, spiroxamin, terbuthylazine and triticonazole. The initial concentration in the treatments and properties of these pesticides are described in Online Resource 1. The mixture was diluted in sterile distilled water and the solution was stirred for $5 \mathrm{~min}$ before being used in the experiments. The concentrations of the pesticides in the solution were determined by method OMK 57 (Jansson and Kreuger 2010), as described below. Total concentration of pesticides was then determined as sum of individual pesticides. Total pesticide concentration at the start of the experiments was $72.7 \pm 1.8 \mu \mathrm{g} / \mathrm{L}$ in all treatments.
Experimental design

Four treatments were included in the study: a sterile control treatment, a microalgal treatment, a fungal treatment and a treatment with biopellets (Table 1).

The control treatment contained equal amounts of BG-11, glucose solution and pesticide solution. The microalgal treatment contained equal amounts of algal stock solution, glucose solution and pesticide solution. The fungal treatment consisted of BG-11, fungal stock solution made in glucose and pesticide solution. The biopellet treatment consisted of algal stock solution, fungal stock solution and pesticide solution. The initial $\mathrm{pH}$ was adjusted to 4.0 in all treatments, using $\mathrm{HCl}$, as this $\mathrm{pH}$ has been identified as optimal for biopellet formation and algal harvest by the fungus A. niger (Zhang and $\mathrm{Hu}$ 2012).

The treatments were placed on a horizontal shaker $(100 \mathrm{rpm})$ at room temperature without additional light. Based on the time it takes to form biopellets (Zhang and $\mathrm{Hu} 2012$ ), a treatment time of $68 \mathrm{~h}$ was applied. After this time, the treatments were removed from the shaker and the biomass produced was collected by filtration through GF/F filters (VWR International, filter no. 698). The control treatment was filtered in the same manner as the other treatments and the water samples for analysis of pesticide levels were stored at $-18{ }^{\circ} \mathrm{C}$. Samples for analysis of chemical oxygen demand (COD) reduction and laccase activity were taken after 0, 24, 48 and $68 \mathrm{~h}$.

Analysis

\section{Growth parameters}

At the start and end of the experiment, dry weight biomass in all treatments was estimated by filtration. A similar volume of each sample was filtered through pre-dried and pre-weighed GF/B filters. The filters were dried at $65{ }^{\circ} \mathrm{C}$ for $2 \mathrm{~h}$ and re-weighed on a precision balance. The control treatment was filtered in the same manner as the other treatments. Specific growth rate (SGR) of the microorganisms used was calculated as (Lawton et al. 2013):

$\mathrm{SGR}=\left[\ln \left(B_{f} / B_{i}\right) \cdot t\right] \cdot 100$ 
Table 1 Dry weight biomass, specific growth rate (SGR) and $\mathrm{pH}$ in the different treatments. Mean and standard deviation are shown

\begin{tabular}{|c|c|c|c|c|c|c|}
\hline \multirow[t]{2}{*}{ Treatment } & \multirow[t]{2}{*}{ Content } & \multicolumn{2}{|c|}{ Biomass (dwt, mg/L) } & \multicolumn{2}{|l|}{$\mathrm{PH}$} & \multirow[t]{2}{*}{ SGR $(\% / h)$} \\
\hline & & Initial & Final & Initial & Final & \\
\hline Control & BG-11, glucose solution, pesticide solution & 0 & 0 & $4.0 \pm 0.0$ & $4.0 \pm 0.0 \mathrm{a}$ & 0 \\
\hline Microalgal & $\begin{array}{l}\text { Microalgal stock solution, glucose solution, } \\
\text { pesticide solution }\end{array}$ & $174.2 \pm 3.9$ & $353.6 \pm 10.2 \mathrm{a}^{*}$ & $4.0 \pm 0.0$ & $4.2 \pm 0.2 \mathrm{a}$ & $1.05 \pm 0.0 \mathrm{a}$ \\
\hline Fungal & $\begin{array}{l}\text { BG- } 11 \text {, fungal stock solution, pesticide } \\
\text { solution }\end{array}$ & $42.9 \pm 9.0$ & $540.0 \pm 27.5 b$ & $4.0 \pm 0.0$ & $3.1 \pm 0.1 b$ & $3.78 \pm 0.3 b$ \\
\hline Biopellet & $\begin{array}{l}\text { Microalgal and fungal stock solution, } \\
\text { pesticide solution }\end{array}$ & $181.6 \pm 8.5$ & $532.9 \pm 21.8 b$ & $4.0 \pm 0.0$ & $3.0 \pm 0.1 b$ & $1.59 \pm 0.1 \mathrm{c}$ \\
\hline
\end{tabular}

*Values within columns followed by different letters are significantly different $(\mathrm{P}<0.05$, Tukey's test)

where $B_{f}$ and $B_{i}$ are the final and initial dry weight biomass concentration $(\mathrm{mg} / \mathrm{L})$ and $t$ is the number of hours in the batch experiment.

For determination of chemical oxygen demand (COD) in the treatments, samples were taken at the start of the experiment and after $24 \mathrm{~h}, 48 \mathrm{~h}$ and $68 \mathrm{~h}$ (the end of the experiment). Aliquots were removed from each replicate, filtered (GF/B filters) and concentration of COD was determined using Hach Lange LCK 014 (ISO 1989). Laccase activity was determined colorimetrically by detecting the product of oxidation of 2,6-dimethoxyphenol (DMP). The analysis was performed as described by Parenti et al. (2013) and the reaction mixture contained $0.45 \mathrm{~mL}$ of the filtered water samples and $0.5 \mathrm{~mL}$ of $10 \mathrm{mM}$ DMP in $100 \mathrm{mM}$ acetate buffer ( $\mathrm{pH} 5)$. After $1 \mathrm{~min}$ of incubation at room temperature, the absorbance at $468 \mathrm{~nm}$ was measured using a DR1900 Hach Portable Spectrophotometer.

\section{Pesticide analysis}

The filtered and frozen water samples were sent to an accredited laboratory at CKB that is responsible for the Swedish national environmental monitoring programme for pesticides. The analytical method used, OMK 57, is based on online SPE extraction and liquid chromatography-tandem mass spectrometry (LC-MS/ MS). This method permits detection of numerous pesticides at low concentrations, as described in detail by Jansson and Kreuger (2010), with recoveries higher than $70 \%$ and limit of quantification (LOQ) values at or below $10 \mathrm{ng} / \mathrm{L}$ for individual pesticides.
Absolute pesticide reduction due to treatment was estimated as the difference between initial concentration in the control treatment and final concentration in the different treatments. The relative pesticide reduction was calculated as:

Relative reduction $=\left(\frac{\left(C_{\text {initial }}-C_{\text {final }}\right)}{C_{\text {initial }}}\right) \times 100$

where $C_{\text {initial }}=$ mean initial concentration of a particular pesticide $(\mu \mathrm{g} / \mathrm{L})$ and $C_{\text {final }}=$ final concentration of that pesticide in a specific treatment $(\mu \mathrm{g} / \mathrm{L})$.

\section{Statistical analysis}

The experiment was set up with three replicates in each treatment and the data obtained were analysed statistically using Minitab 16 for Windows. In order to inspect the data for homogeneity of variance and normal distribution, the Levene and KolmogorovSmirnov test, respectively, was used. One-way Anova followed by Tukey's multiple comparison test was employed to test for effects of treatment on final concentrations of pesticides in the water. The significance level was set to $p<0.05$ in all cases.

\section{Results and discussion}

Growth parameters

This study was performed under conditions previously identified as optimal for biopellet formation and algal harvest by the fungus $A$. niger, i.e. low $\mathrm{pH}$, addition of a suitable carbon source and no additional light (Zhang 
and $\mathrm{Hu}$ 2012). From a practical perspective, these conditions should be applied after microalgal growth in wastewater, since the environment created is less suited for microalgal growth. However, biomass production was observed in all treatments except the control, which was kept under sterile conditions (Table 1). The observed biomass production in the microalgal treatment (Table 1) was probably because the microalgae in the stock solution were in their exponential growth phase when the experiment started. Specific growth rate was significantly different between the treatments, with the highest values observed for the fungal treatment and the lowest for the microalgal treatment (Table 1). This difference reflects the environmental conditions, which were suboptimal for the microalgae, whereas A. niger is well-known for growth at low $\mathrm{pH}$ and with capability for growth down to $\mathrm{pH} 2$ (Pitt 1981).

Fungal growth in treatments involving the fungus was also reflected in decreased COD concentration in those treatments (Fig. 1). After $68 \mathrm{~h}$, the COD concentration had been lowered by $9.1 \%$ in the fungal treatment and $14.6 \%$ in the biopellet treatment, compared with the initial value. This decrease was significantly higher for the biopellet treatment than the fungal treatment, despite the final amount of biomass not differing between these treatments (Table 1). As C. vulgaris has the capability for mixotrophy (Lia et al. 2014), a possible explanation for the significantly higher decrease in COD concentration in the biopellet treatment is that the microalgal cells were protected from the unfavourable low $\mathrm{pH}$ environment when entrapped in the fungal biomass and showed

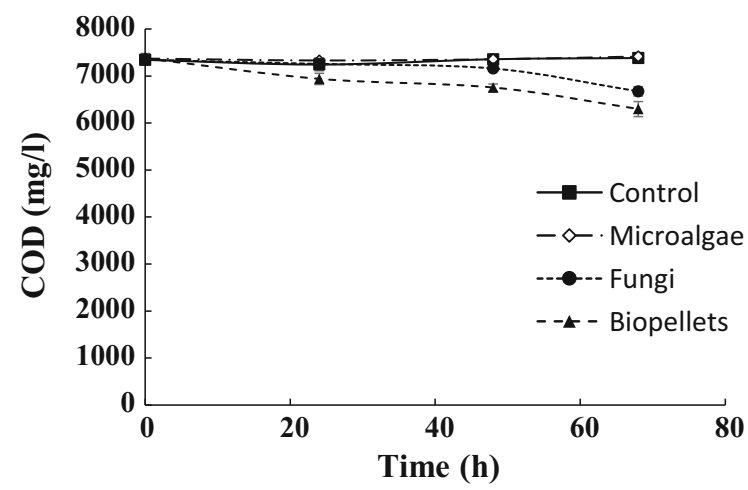

Fig. 1 Decrease in chemical oxygen demand (COD) concentration over time in the treatments. Mean and standard deviation (bars) are shown heterotrophy in the absence of light. As expected, there was no decrease in COD concentration in the control treatment and the microalgal treatment.

A change in the initial $\mathrm{pH}$ was observed during the experiments, with a significant decrease in the fungal and biopellet treatments compared with the control (Table 1). Aspergillus niger is well-known for production of extracellular enzymes and citric acid, and is used commercially for production of the latter (Yakout 2014). The significantly lower $\mathrm{pH}$ values found in the fungal and biopellet treatments confirm that the fungus was metabolically active.

Aspergillus niger has also been suggested as a good source of laccase, a multicopper oxidase with several biotechnological applications (Tamayo Ramos et al. 2011). Fungal laccases are used for lignin degradation/modification during growth, but these enzymes have low substrate specificity and act upon a wide range of complex molecules (Rhodes 2014). They are therefore of interest for degradation of recalcitrant xenobiotics, and high production has been demonstrated in environments with low $\mathrm{pH}$ (Viswanath et al. 2014). In the present study, no production of extracellular laccases was observed in either of the treatments with the fungus when assayed with the substrate DMP. Different substrate specificity for the laccases produced by A. niger was observed in the study by Tamayo Ramos et al. (2011) and therefore production of laccase cannot be completely ruled out.

Effects of treatments on total amount of pesticides in water

As mentioned, the total amount of pesticides in the water samples was $72.7 \pm 1.8 \mu \mathrm{g} / \mathrm{L}$ when the experiment started. Removal over time due to abiotic factors was observed and, when the experiment ended after $68 \mathrm{~h}$, the concentration of pesticides in the untreated sterile control was $66.6 \pm 1.0 \mu \mathrm{g} / \mathrm{L}$. At the end of the experiment, the total concentration of pesticides in the algal treatment was $67.3 \pm 1.2 \mu \mathrm{g} / \mathrm{L}$ and did not differ significantly from that in the sterile control. In the fungal treatment and the biopellet treatment, the final total pesticide concentration was $59.6 \pm 2.0 \mu \mathrm{g} / \mathrm{L}$ and $56.1 \pm 2.8 \mu \mathrm{g} / \mathrm{L}$, respectively, which was significantly lower than in the algal treatment and the sterile control. These results clearly indicate that, under conditions favourable for fungal-assisted algal harvesting, the fungal species was solely responsible for 
the pesticide reduction. It should also be pointed out that initial dry weight biomass of the microorganisms used for treatment in the present study (Table 1) was between 10- and 100-fold lower than the biomass amount used in activated sludge processes at wastewater treatment plants, which is normally within the range 2-13 g/L (Serrano et al. 2011; Falås et al. 2013). Thus, despite the low amounts of fungus and biopellets used in treatments, significant pesticide removal was observed.

In a previous study using a similar experimental setup and focusing on the effect of microalgae, a significant decrease in pesticide concentrations in water was observed after 4 days of microalgal cultivation (Hultberg et al. 2016). That study was performed in an environment favourable for microalgal growth, with added light and neutral $\mathrm{pH}$. As previously pointed out, one of the most interesting aspects of biopellet formation is its potential to assist in microalgal harvesting. Thus, the organic pollutant removal potential of fungal treatment observed in this study and that of actively growing microalgae reported in our previous study should be considered in combination. In parallel with the benefit of biomass production, microalgal-based wastewater treatment offers an interesting technique for removal of organic pollutants (Matamoros et al. 2015; Hultberg et al. 2016). The present study demonstrates that fungal-assisted microalgal harvesting based on biopellets has the potential to remove organic pollutants from wastewaters.

\section{Effect of treatments on individual pesticides}

Of the 38 pesticides analysed, the concentrations of 17 were found to be reduced significantly after $68 \mathrm{~h}$ of biological treatment compared with a sterile control (Table 2). All of these were reduced in the biopellet treatment with the exception of cyazofamid, which was only reduced in the fungal treatment. Concentrations of the pesticides that were significantly removed in the biopellet treatment are shown in Fig. 2. All of the pesticides removed were associated with the biopellet/fungal treatments and none was only removed in the microalgal treatment.

The pesticides difenoconazole, carfentrazone ethyl, phenmedipham and trinexapac ethyl were removed to below the detection limit after treatment with biopellets (Fig. 2). A previous study has shown complete, or very high, removal of these pesticides by biosorption to dead algal biomass (carfentrazone ethyl, phenmedipham) or by an actively growing microalgal culture (carfentrazone ethyl, difenconazole, trinexapac ethyl) (Hultberg et al. 2016). The results obtained in this study confirm that these pesticides are sensitive to biological treatment. The majority of pesticides that were significantly removed by the biopellet treatment belonged to the substance groups triazinones and triazoles, which are reported to be both toxic to aquatic organisms and frequently detected in aquatic environments (Loos et al. 2010a, b).

In the microalgal treatment, two of the significantly reduced pesticides, carfentrazone ethyl and phenmedipham, underwent relative removal of $50 \%$ or more compared with the control (Table 2). High removal of these two pesticides has previously been shown following short-term $(1 \mathrm{~h})$ exposure to dead microalgal biomass (Hultberg et al. 2016), suggesting rapid sorption to algal cell walls. Despite significant removal of these two pesticides, no effect was seen on total concentration of pesticides in the algal treatment and it should be pointed out that microalgal removal of pesticides was negligible under the conditions applied.

The fungal treatment removed three additional pesticides (cyanazine, difenoconazole and trinexapac ethyl) by $50 \%$ or more. The biopellet treatment achieved a $50 \%$ decrease in the concentrations of two additional pesticides (carbofuran and terbuthylazine). Synergistic effects were indicated for these two pesticides, where relative removal of more than $50 \%$ was achieved by the biopellet treatment, while considerably lower removal was observed after the microalgal and fungal treatments (Fig. 3; Table 2). This indicates that the microalgal component in the biopellets may have had an effect in removal of specific pesticides. Within the context of persistence in surface water environments, terbuthylazine, which had a relative removal rate of $66 \%$ in the biopellet treatment, is one of the most frequently detected pesticides (Loos et al. 2010a, b).

\section{Conclusions}

Algae-based technologies for treatment of wastewater are of interest, but harvesting of the microalgae is a bottleneck. A promising aspect of biopellet formation is its potential to assist in microalgal harvesting. A 
Table 2 All pesticides with significantly lower concentrations compared with the control after treatment. Pesticides in italics had a removal rate of $50 \%$ or more compared with the control. Water containing 38 different pesticides was used in the study

*Not significantly lower compared with the control treatment $(\mathrm{P}<0.05$, Tukey's test)

Fig. 2 Concentrations of pesticides which were significantly decreased by the biopellet treatment compared with the concentration in the control treatment. Mean and standard deviation (bars) are shown

\begin{tabular}{llll}
\hline Treatment & Biopellet & Fungal & Microalgal \\
\hline Carbofuran & Carbofuran & $*$ \\
Carfentrazone ethyl & Carfentrazone ethyl & Carfentrazone ethyl \\
Cyanzine & Cyanzine & $*$ \\
$*$ & Cyazofamid & $*$ \\
Difenoconazole & Difenoconazole & $*$ \\
Fludioxonil & Fludioxonil & Fludioxonil \\
Flurprimidol & Flurprimidol & $*$ \\
Flusilazol & $*$ & $*$ \\
Flutriafol & $*$ & $*$ \\
Hexazinone & Hexazinone & $*$ \\
Metamitron & $*$ & $*$ \\
Penconazole & $*$ & $*$ \\
Phenmedifam & Phenmedifam & Phenmedifam \\
Prothioconazole-destio & Prothioconazole-destio & $*$ \\
Terbutylazine & $*$ & $*$ \\
Trinexapac-ethyl & Trinexapac-ethyl & $*$ \\
Triconazole & Triconazole & $*$ \\
16 (of 38) & 12 (of 38) & 3 (of 38) \\
\hline & &
\end{tabular}

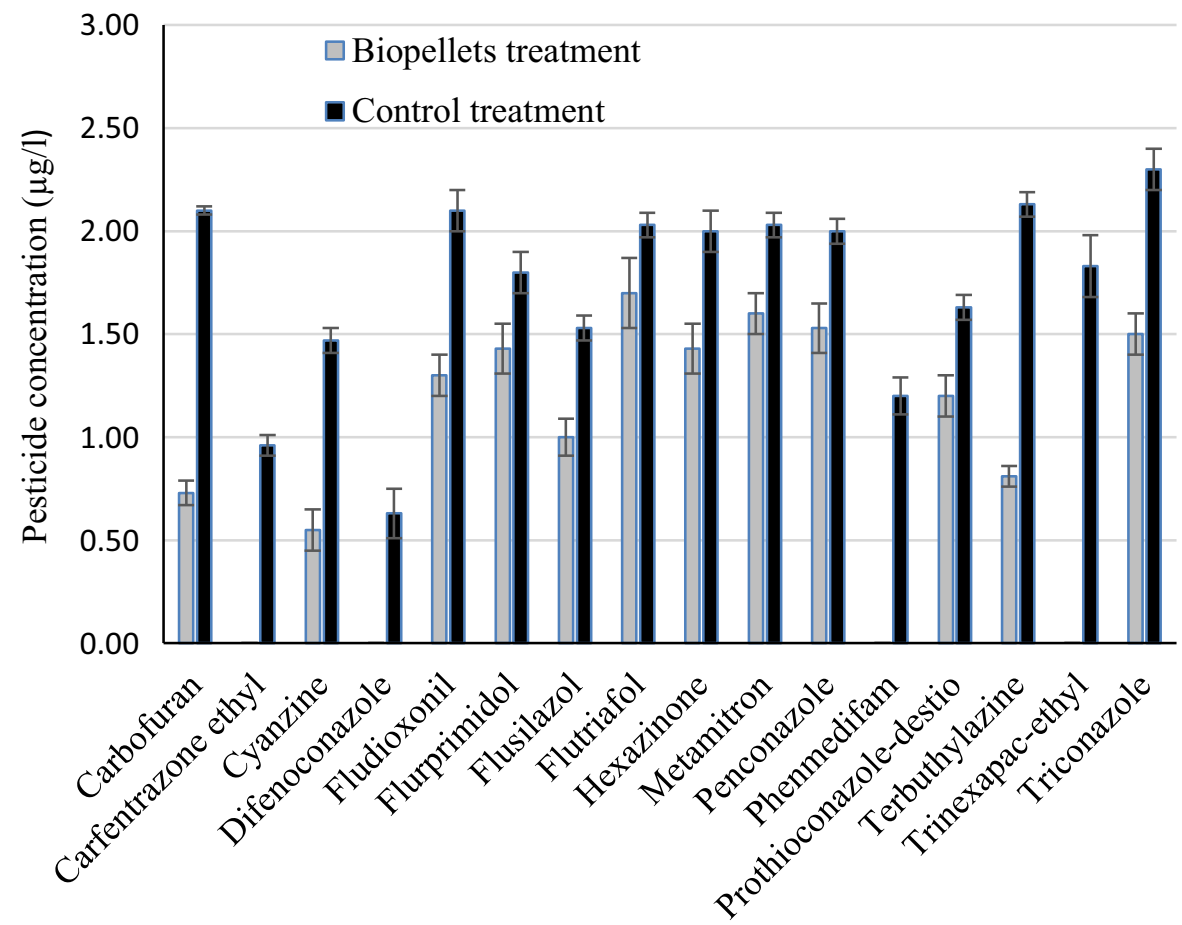

significant decrease in pesticide concentrations in water was observed after treatment with the filamentous fungus Aspergillus niger or with biopellets composed of the microalga Chlorella vulgaris and $A$. niger. Based on these findings, it can be concluded that fungal-assisted algal harvesting through biopellet formation increases the scope for removal of organic pollutants from wastewater. Under the conditions 


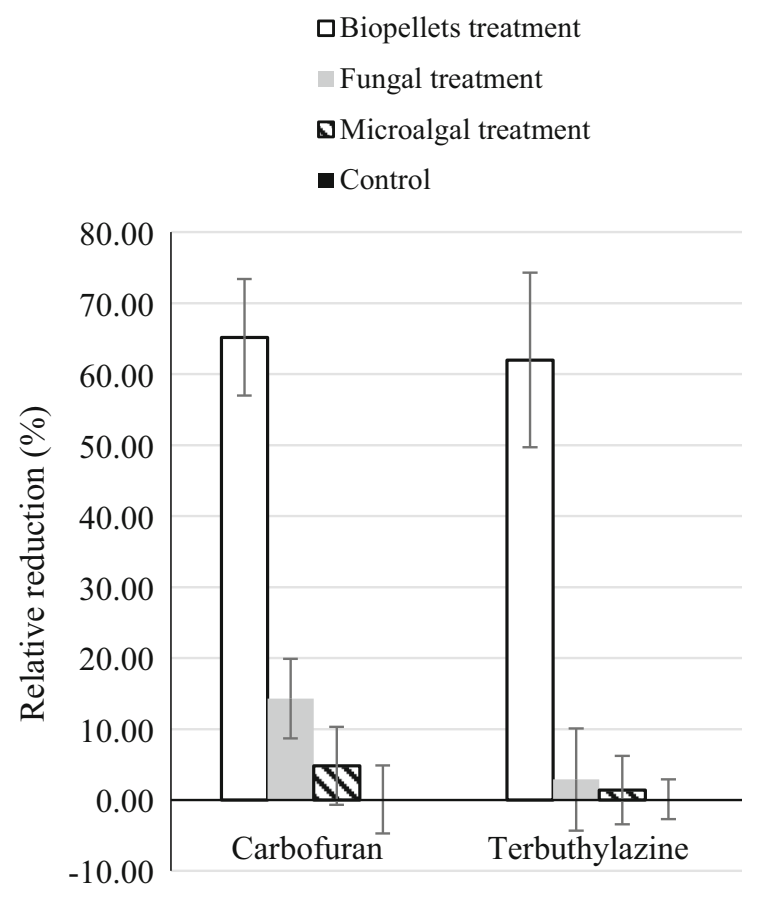

Fig. 3 Relative reduction in carbofuran and terbuthylazine concentrations in the treatments. Mean and standard deviation (bars) are shown

applied here, the fungal species was solely responsible for the pesticide reduction.

Acknowledgements The authors would like to thank the EU and FORMAS for funding, within the framework of the collaborative international consortium REWATER funded under the ERA-NET Cofund WaterWorks2015 Call. This ERA-NET is an integral part of the 2016 Joint Activities developed by the Water Challenges for a Changing World Joint Programme Initiative (Water JPI).

Funding This study was funded by EU and FORMAS (Grants 2017-00021; 2017-00022) within the framework of the collaborative international consortium REWATER funded under the ERA-NET Cofund WaterWorks2015 Call. This ERA-NET is an integral part of the 2016 Joint Activities developed by the Water Challenges for a Changing World Joint Programme Initiative (Water JPI).

\section{Compliance with ethical standards}

Conflict of interest The authors declare that they have no conflict of interest.

Ethical approval This article does not contain any studies with human participants or animals performed by any of the authors.
Open Access This article is distributed under the terms of the Creative Commons Attribution 4.0 International License (http:// creativecommons.org/licenses/by/4.0/), which permits unrestricted use, distribution, and reproduction in any medium, provided you give appropriate credit to the original author(s) and the source, provide a link to the Creative Commons license, and indicate if changes were made.

\section{References}

Bhattacharya A, Mathur M, Kumar P, Kumar Prajapati S, Malik A (2017) A rapid method for fungal assisted algal flocculation: critical parameters and mechanism insights. Algal Res 21:42-51

Cai X, Liu W, Jin M, Lin K (2007) Relation of diclofop-methyl toxicity and degradation in algae cultures. Environ Toxicol Chem 26:970-975

EC (2013) Directive 2013/39/EU of the European Parliament and of the Council of 12 August 2013 amending Directives 2000/60/EC and 2008/105/EC as regards priority substances in the field of water policy. http://eur-lex.europa. eu/legal-content/EN/ALL/?uri=CELEX:32013L0039

EC (2015) Commission implementing decision (EU) 2015/495 of 20 March 2015 establishing a watch list of substances for Union-wide monitoring in the field of water policy pursuant to Directive 2008/105/EC of the European Parliament and of the Council. http://eur-lex.europa.eu/legalcontent/EN/TXT/PDF/?uri=CELEX:32015D0495\&from= EN

Falås P, Longrée P, La Cour Jansen J, Siegrist H, Hollender J, Joss A (2013) Micropollutant removal by attached and suspended growth in a hybrid biofilm-activated sludge process. Water Res 47:4498-4506

Fomina M, Gadd GM (2014) Biosorption: current perspectives on concept, definition and application. Biores Technol 160:3-14

Gentili FG (2014) Microalgal biomass and lipid production in mixed municipal, dairy, pulp and paper wastewater together with added flue gases. Biores Technol 169:27-32

Hollender J, Zimmermann SG, Koepke S, Krauss M, Mcardell CS, Oer C, Singer H, Von Guten U, Siegrist H (2009) Elimination of organic micropollutants in a municipal wastewater treatment plant upgraded with a full-scale postozonation followed by sand filtration. Environ Sci Technol 43:7862-7869

Hultberg M, Bodin H, Ardal E, Asp H (2016) Effect of microalgal treatments on pesticides in water. Environ Technol 37:893-898

ISO (1989) Water quality-determination of the chemical oxygen demand (ISO 6060). International Organization for Standardization, Geneva, Switzerland. http://www.iso.org/ iso/home/store/catalogue_tc/catalogue_detail. htm?csnumber $=12260$

Jansson C, Kreuger J (2010) Multiresidue analysis of 95 pesticides at low nanogram/liter levels in surface waters using online preconcentration and high performance liquid 
chromatography/tandem mass spectrometry. J AOAC Int 93:1732-1747

Jones OAH, Voulvoulis N, Lester JN (2005) Human pharmaceuticals in wastewater treatment processes. Crit Rev Environ Sci Technol 35:401-427

Kreuger J, Graaf S, Patring J, Adielsson S (2010) Pesticides in surface water in areas with open ground and greenhouse horticultural crops in Sweden 2008. Swedish University of Agricultural Sciences, Division of Water Quality Management. Ekohydrologi 117. http://www-mv.slu.se/ webfiles/vv/CKB/Ekohydrologi_117_ENG.pdf

Lawton RJ, Mata L, de Nys R, Paul NA (2013) Algal Bioremediation of waste waters from land-based aquaculture using ulva: selecting target species and strains. PLoS ONE 8(10):e77344. https://doi.org/10.1371/journal.pone. 0077344

Lia YR, Tsaia WT, Hsub YC, Xiec MZ, Chend JJ (2014) Comparison of autotrophic and mixotrophic cultivation of green microalgal for biodiesel production. Energy Procedia 52:371-376

Loos R, Gawlik BM, Locoro G, Rimaviciute E, Contini S, Bidoglio G (2009) EU-wide survey of polar organic persistent pollutants in European river waters. Environ Pollut 157:561-568

Loos R, Locoro G, Comero S, Contini S, Schwesig D, Werres F, Balsaa P, Gans O, Weiss S, Blaha L, Bolchi M, Gawlik BM (2010a) Pan-European survey on the occurrence of selected polar organic persistent pollutants in ground water. Water Res 44:4115-4126

Loos R, Locoro G, Contini S (2010b) Occurrence of polar organic contaminants in the dissolved water phase of the Danube River and its major tributaries using SPE-LC-MS2 analysis. Water Res 44:2325-2335

Masiá A, Campo J, Vázquez-Roig P, Blasco C, Picó Y (2013) Screening of currently used pesticides in water, sediments and biota of the Guadalquivir River Basin (Spain). J Hazard Mater 263:95-104

Matamoros V, Gutiérrez R, Ferrer I, Garcia J, Bayona JM (2015) Capability of microalgae-based wastewater treatment systems to remove emerging contaminates: a pilot-scale study. J Hazard Mater 288:34-42

Muñoz R, Guieysse B (2006) Algal-bacterial processes for the treatment of hazardous contaminants: a review. Water Res 40:2799-2815

Oswald WJ (1988) Microalgae and wastewater treatment. In: Borowitzka MA, Borowitzka LJ (eds) Microalgal biotechnology. Cambridge University Press, Cambridge, pp 305-328

Parenti A, Muguerza E, Redin Iroz A, Omarini A, Conde E, Alfaro M, Castanera R, Santoyo F, Ramírez L, Pisabarro AG (2013) Induction of laccase activity in the white rot fungus Pleurotus ostreatus using water polluted with wheat straw extracts. Biores Technol 133:142-149

Pereira AMPT, Silva LJG, Meisel LM, Lino CM, Pena A (2015) Environmental impact of pharmaceuticals from Portuguese wastewaters: geographical and seasonal occurrence, removal and risk assessment. Environ Res 136:108-119

Pinto AP, Serrano C, Pires T, Mestrinho E, Dias L, Teixeira DM, Caldeira AT (2012) Degradation of terbuthylazine, difenoconazole and pendimethalin pesticides by selected fungi cultures. Sci Total Environ. https://doi.org/10.1016/j. scitotenv.2012.07.027

Pitt JI (1981) Food spoilage and biodeterioration. In: Cole GT, Kendrick B (eds) Biology of conidial fungi, vol 2. Academic Press, New York, pp 111-142

Rhodes CJ (2014) Mycoremediation (bioremediation with fungi)_-growing mushrooms to clean the earth. Chem Speciat Bioavailab 26:196-198

Serrano D, Suárez S, Lema JM, Omil F (2011) Removal of persistent pharmaceutical micropollutants from sewage by addition of PAC in a sequential membrane bioreactor. Water Res 45:5323-5333

Shilton AN, Powell N, Guieysse B (2012) Plant based phosphorus recovery from wastewater via algae and macrophytes. Curr Opin Biotechnol 23:884-889

Tamayo Ramos JA, Barends S, Verhaert RMD, de Graff LH (2011) The Aspergillus niger multicopper oxidase family: analysis and overexpression of laccase like encoding genes. Microb Cell Fact 10:78. https://doi.org/10.1186/ 1475-2859-10-78

Uduman N, Qi Y, Danquah MK, Forde GM, Hoadley A (2010) Dewatering of microalgal cultures: a major bottleneck to algae-based fuels. J Renew Sustain Energy 2:012701. https://doi.org/10.1063/1.3294480

Viswanath B, Rajesh B, Janardhan A, Kumar AP, Narasimha (2014) Fungal laccases and their application in bioremediation. Enzyme Res. https://doi.org/10.1155/2014/163242

Yakout SM (2014) Review on the bioremediation by Aspergillus niger. J Pure Appl Microbiol 8:109-116

Zhang J, Hu B (2012) A novel method to harvest microalgae via co-culture of filamentous fungi to form cell pellets. Biores Technol 114:529-535 